Paper ID \#19450

\title{
Why not just run this as a demo? Differences in students' conceptual under- standing after experiments or demonstrations
}

\author{
Dr. Margot A Vigeant, Bucknell University
}

Margot Vigeant is a professor of chemical engineering at Bucknell University. She earned her B.S. in chemical engineering from Cornell University, and her M.S. and Ph.D., also in chemical engineering, from the University of Virginia. Her primary research focus is on engineering pedagogy at the undergraduate level. She is particularly interested in the teaching and learning of concepts related to thermodynamics. She is also interested in active, collaborative, and problem-based learning, and in the ways hands-on activities such as making, technology, and games can be used to improve student engagement.

\section{Dr. Michael J. Prince, Bucknell University}

Dr. Michael Prince is a professor of chemical engineering at Bucknell University and co-director of the National Effective Teaching Institute. His research examines a range of engineering education topics, including how to assess and repair student misconceptions and how to increase the adoption of researchbased instructional strategies by college instructors and corporate trainers. He is actively engaged in presenting workshops on instructional design to both academic and corporate instructors.

\section{Dr. Katharyn E. K. Nottis, Bucknell University}

Dr. Nottis is an Educational Psychologist and Professor of Education at Bucknell University. Her research has focused on meaningful learning in science and engineering education, approached from the perspective of Human Constructivism. She has authored several publications and given numerous presentations on the generation of analogies, misconceptions, and facilitating learning in science and engineering education. She has been involved in collaborative research projects focused on conceptual learning in chemistry, chemical engineering, seismology, and astronomy.

\section{Dr. Milo Koretsky, Oregon State University}

Milo Koretsky is a Professor of Chemical Engineering at Oregon State University. He received his B.S. and M.S. degrees from UC San Diego and his Ph.D. from UC Berkeley, all in Chemical Engineering. He currently has research activity in areas related engineering education and is interested in integrating technology into effective educational practices and in promoting the use of higher-level cognitive skills in engineering problem solving. His research interests particularly focus on what prevents students from being able to integrate and extend the knowledge developed in specific courses in the core curriculum to the more complex, authentic problems and projects they face as professionals. Dr. Koretsky is one of the founding members of the Center for Lifelong STEM Education Research at OSU.

\section{Mr. Edward C Bent, Bucknell University}

Edward Bent is currently an undergraduate student at Bucknell University majoring in chemical engineering.

\section{Rachel Cincotta, Bucknell University}

Rachel Cincotta is a student at Bucknell University pursuing a BS in Chemical Engineering.

\section{Kyle Andrew MacDougall, Bucknell University Chemical Engineering Department}

Currently a Chemical Engineering student with a process concentration in Bucknell University's class of 2017. Throughout my studies at Bucknell I have gained many areas of interest, especially in the fields of food science, pharmaceutical engineering, and material science. After graduation I plan on pursuing a career as a process engineer, either in the food or pharmaceutical industries. Ideally I would like to be working as a process engineer on a chocolate production system. 


\section{Why not just run this as a demo? Differences in students' conceptual understanding after experiments or demonstrations}

Chemical engineering enrollments have ballooned in the past five years, making it increasingly challenging to find physical space for undergraduate student laboratory experiences. Rather than have laboratory sections with core chemical engineering courses such as fluid mechanics or heat transfer, most students' in-major laboratory experience is limited to a unit operations laboratory course. Our previous work demonstrated that inquiry-based laboratory activities, brief hands-onexperiments designed to directly combat common misconceptions, could be highly effective at repairing students' misconceptions. However, even brief experiments present logistical challenges for many colleagues. Therefore we undertook a study asking the question: What is the effectiveness of the same activities if performed as demonstrations?

Over 200 heat transfer students at three institutions were given the Heat and Energy Concept Inventory (HECI) at both the start and end of the semester. During the semester, instructors either had students complete four brief laboratory experiments designed to repair common misconceptions in two areas of heat transfer or had students watch demonstrations of the same experiments as demonstrations. Both treatments were accompanied with the same pre-lab prediction questions and post-lab assessment and reflection questions, which kept student time devoted to each activity similar. Students performing the experiment in small groups scored higher on the concept inventory than did students who watched a demonstration (24.7-percentage point increase relative to 16.9-percentage point increase) although both groups improved significantly relative to their pre-test scores. Analysis of the student reflection questions mirrored this trend, with students performing experiments answering the reflection questions more fully and more correctly than students who watched the demonstration. 


\section{Introduction and Background}

In the past five years, Chemical Engineering departments in the United States have been under intense enrollment pressure with over half of reporting departments responding that undergraduate enrollment has doubled (1). Enrollment increases are often felt most keenly in laboratory sections, where safety considerations and the availability of equipment limits the number of students who may participate in experiments at any one time. One possible response to these constraints is to take some experiments that were previously performed by students and instead present them as in-class demonstrations.

Laboratories have a range of educational outcomes associated with them, including developing interest, promoting problem-solving and trouble-shooting, enabling verification of established theory, modeling the experiences of professionals, and conceptual learning (2-4). Active learning has a number of benefits for student learning (5), and to many it seems self-evident that laboratories are both active and excellent learning spaces for engineering. While it would be challenging for a demonstration to replicate the kinesthetic or trouble-shooting aspects of laboratory experiences, it should be possible for appropriately constructed demonstrations to allow students to actively construct understanding in the more abstract outcomes from laboratory experience such as verification of theory and conceptual learning.

In earlier work, we established a series of inquiry-based laboratory activities (IBLAs) that significantly increased students' conceptual learning in heat transfer and thermodynamics (611). Two IBLAs were created for each of nine conceptual areas where undergraduate chemical engineers commonly held misconceptions. Figure 1 shows an example of one such activity, a small experiment intended to address misconceptions about the factors impacting the rate of heat transfer and how these factors differ from those that impact the amount of energy ultimately transferred (Rate vs. Amount). Students often assume that faster will automatically translate to more. The chipped ice vs. snowball experiment clearly demonstrates that just because the water cools more rapidly with chipped ice, the final water temperature is the same for the same mass of ice whether it be chipped or a single large "snowball."

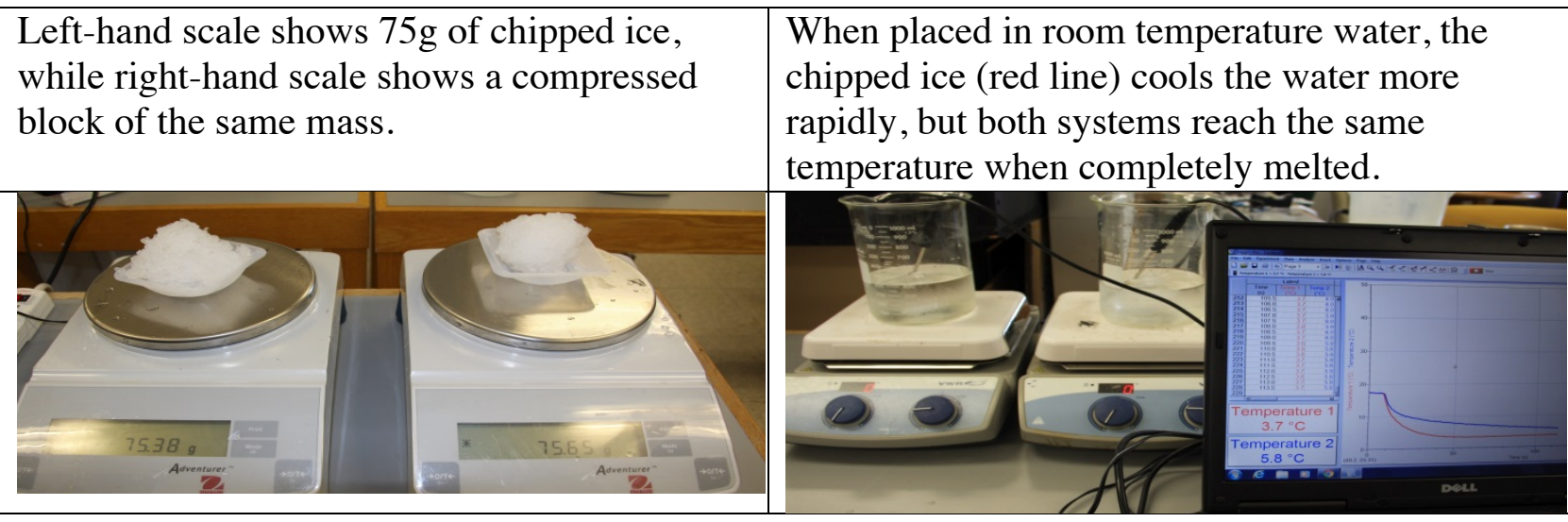

Figure 1: Chipped ice vs. Snowball activity in support of the "rate vs. amount" concept

Despite positive results from IBLAs, colleagues at other institutions were reluctant to adopt the IBLAs for their courses. Colleagues indicated that they might be able to use the IBLAs if they 
could instead run them as a demonstration. While this seemed to be a reasonable change, we did not know if such a change would alter the impact of the IBLAs on student learning, and if so, by how much. The specific goal of the work described here is to assess if students learn as much from demonstrations of conceptual learning activities as they would from performing the activities themselves.

\section{Methods}

The present study focuses on two conceptual areas in heat transfer. The first, Rate vs. Amount, is described above. The second is Radiation, where students commonly hold the misconception that color has a far greater impact on radiative heat transfer than it actually does.

Heat transfer instructors at four institutions in the United States, two large-public, two smallerprivate, volunteered their classes for the study. Within the first two weeks of the semester or quarter, students were given a heat transfer concept inventory (HECI, (9)). During the semester, four IBLAs were implemented, two each in the concept areas of Rate vs. Amount and Radiation. All students followed the same IBLA structure, completing predictions before the experimental portion of the activity, answering a few observation questions during the experimental portion, and concluding with reflection questions afterwards. Two IBLA modes were compared "student experiment" in which students performed the activities themselves within small groups and "demonstration" or "demo" in which students watched instructors complete the experiment. It should be noted that one of the activities in the rate vs. amount concept area is impractical as a physical experiment or demonstration and so is always presented as a simulation (or demonstration of the simulation). For any given IBLA, all students in the same course used the IBLA in the same delivery mode. Within two weeks of the end of the semester, students again took the HECI.

The HECI is a multiple-choice instrument with validated subscales that cover four concept areas in heat transfer, including the two highlighted in this work. For the analysis of HECI data, student responses were dichotomized into correct and incorrect responses. Students pre- and post- test scores were paired and compared to determine change over the course of the semester or quarter. Responses on the HECI as a whole were considered, as were responses on the relevant sub-tests within the HECI. Students' HECI pre-test score was taken as an indication of their preparation, and any differences between institutions were controlled for statistically in the analysis.

Student reflection responses were also analyzed. These written responses were captured via Google Form and were generally one to three sentences in length. Such responses were available for three of the four IBLAs used, both radiation activities and the "chipped ice vs. snowball" rate vs. amount activity. The analysis of these responses, used a rubric to group responses into "totally incorrect," "mostly incorrect," "mostly correct," and "entirely correct." A content expert was consulted to construct exemplar answers for each of the categories. A team of three raters assessed each answer, and interrater-reliability was established by a training set where each evaluator assessed each independently, then discussed any discrepant results until they reached consensus. 


\section{Results and Discussion}

Table 1 shows concept inventory results for all participants. Concept inventory scores for both groups of students improved significantly between pre- and post- test, and significantly greater improvement was seen (24.7 percentage points) for the student-experiment group relative to the "demo" group (16.9 percentage points). For comparison, students in heat transfer courses with no IBLAs scored $39.3 \%$ in the HECI pre-test and $42.6 \%$ on the post-test, for a 5.7 percentage point increase which was statistically significant but with a small effect size $(d=0.19)(12)$.

Table 1: HECI Results

\begin{tabular}{|c|c|c|c|c|c|c|}
\hline \multirow[t]{2}{*}{$\begin{array}{l}\text { Type of } \\
\text { Instruction }\end{array}$} & \multicolumn{2}{|c|}{$\begin{array}{l}\text { Total Heat Transfer } \\
\text { Concept Inventory }\end{array}$} & \multicolumn{2}{|c|}{$\begin{array}{c}\text { Rate vs. Amount Sub- } \\
\text { test }\end{array}$} & \multicolumn{2}{|c|}{ Radiation Sub-test } \\
\hline & $\begin{array}{l}\text { Mean } \\
\text { Pre-Test } \\
\text { Score } \\
\text { (std.dev) }\end{array}$ & \begin{tabular}{|l|} 
Mean \\
Post-Test \\
Score \\
(std.dev)
\end{tabular} & $\begin{array}{l}\text { Mean } \\
\text { Pre-Test } \\
\text { Score } \\
\text { (std.dev) }\end{array}$ & $\begin{array}{l}\text { Mean } \\
\text { Post-Test } \\
\text { Score } \\
\text { (std.dev) }\end{array}$ & $\begin{array}{l}\text { Mean } \\
\text { Pre-Test } \\
\text { Score } \\
\text { (std.dev) }\end{array}$ & $\begin{array}{l}\text { Mean } \\
\text { Post-Test } \\
\text { Score } \\
\text { (std.dev) }\end{array}$ \\
\hline $\begin{array}{l}\text { Faculty } \\
\text { Demonstration of } \\
\text { Physical } \\
\text { Experiment }\end{array}$ & $\begin{array}{l}41.2 \% \\
(14.9 \%) \\
\mathrm{n}=80\end{array}$ & $\begin{array}{l}58.1 \% \\
(16.7 \%) \\
\mathrm{n}=73\end{array}$ & \begin{tabular}{|l|}
$27.4 \%$ \\
$(25.5 \%)$ \\
$\mathrm{n}=79$
\end{tabular} & $\begin{array}{l}60.3 \% \\
(27.0 \%) \\
\mathrm{n}=73\end{array}$ & $\begin{array}{l}37.3 \% \\
(15.5 \%) \\
\mathrm{n}=79\end{array}$ & $\begin{array}{l}55.5 \% \\
(21.6 \%) \\
\mathrm{n}=73\end{array}$ \\
\hline $\begin{array}{l}\text { Students Doing } \\
\text { Physical } \\
\text { Experiment }\end{array}$ & $\begin{array}{l}47.2 \% \\
(14.3 \%) \\
n=88\end{array}$ & $\begin{array}{l}71.9 \% \\
(17.7 \%) \\
n=85\end{array}$ & $\begin{array}{l}35.1 \% \\
(27.3 \%) \\
n=88\end{array}$ & $\begin{array}{l}72.3 \% \\
(24.6 \%) \\
n=83\end{array}$ & $\begin{array}{l}41.9 \% \\
(16.0 \%) \\
n=88\end{array}$ & $\begin{array}{l}72.4 \% \\
(20.5 \%) \\
n=82\end{array}$ \\
\hline
\end{tabular}

A univariate analysis of variance (ANOVA) was done using instructional method (experiment done by students vs. faculty demonstration of experiment) as the independent variable and Rate vs. Amount and Radiation Post Sub-tests as the dependent variables in separate analyses. With Rate vs. Amount, there was no significant difference between the two instructional groups on the pre-test so a oneway analysis of variance (ANOVA) was done. The Rate vs. Amount Post-Subtest scores of the Physical Experiment Done by Students group was significantly higher than Faculty Demonstration with a small effect size, $\mathrm{F}(1,154)=8.93, \mathrm{p}<.01$, partial $\eta^{2}=.06$.

With Radiation, there was no significant difference between the two instructional groups on the pre-test, and a oneway ANOVA showed that the Radiation Post-Sub-test scores of the Physical Experiment Done by Students group were significantly higher than Faculty Demonstration with a large effect size, $\mathrm{F}(1,153)=27.00, \mathrm{p}<.01$, partial $\eta^{2}=.15$. Because the difference between the two groups on the Radiation pre-test approached significance, a univariate analysis of covariance (ANCOVA) was also performed. The analysis yielded a significant main effect for the instructional method with a medium effect size; $\mathrm{F}(1,150)=22.23$, $\mathrm{p}<.01$, partial $\eta^{2}=.13$. The covariate of the radiation pre-test score significantly influenced, with a small effect size, the dependent variable of the radiation post-test score; $\mathrm{F}(1,150)=8.98, \mathrm{p}<.01$, partial $\eta^{2}=.06$. 
Instructional method remained a significant factor in students' performance on the radiation posttest even when radiation pre-test scores were controlled.

Figure 2 shows the results of students' written responses to the reflection questions. Students who provided correct answers that were lacking in key details would have received a score of $2 / 3$ (0.67) on the scale shown - for example, in the case of the "chipped ice vs. snowball" IBLA, a $2 / 3$ answer would note that "surface area is related to rate" but a $3 / 3$ answer would go on to say that it is not related to amount of energy transferred. In this assessment taken as a whole, the student experiment mode of the IBLA again outperforms the faculty demonstration mode. However, looking at the outcomes from each IBLA individually, it is clear the differences in performance are not uniform and the performance on the "heat lamp" activity is nearly identical in both modes.

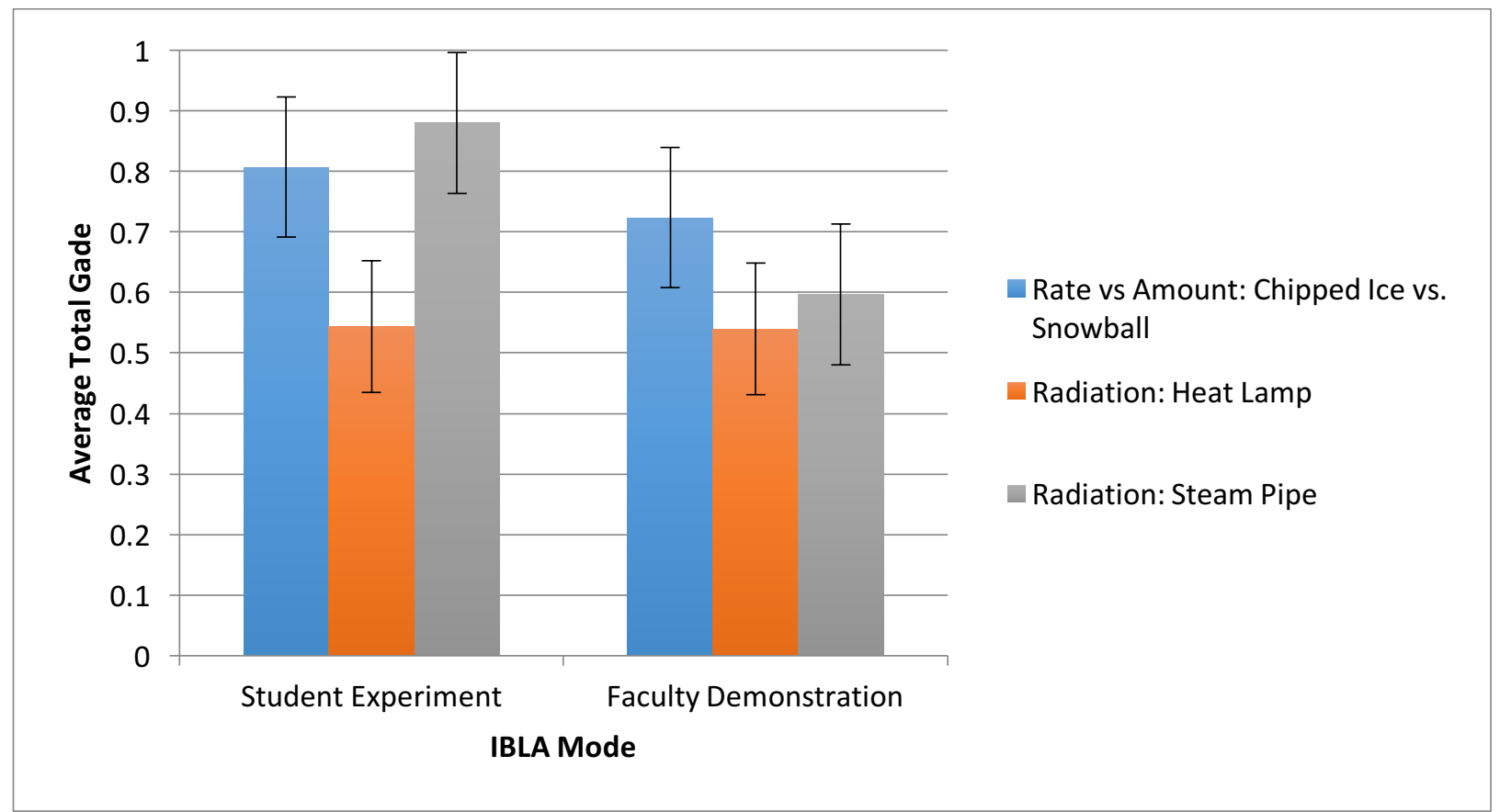

Figure 2: Average total score on reflection questions by activity and mode. Error bars indicate standard deviation.

Both the qualitative and quantitative answers must be considered in order to understand students' level of conceptual change after the IBLAs. The HECI has more questions in each concept area that probe student understanding in several situations and directly target common misconceptions. The qualitative results ask only about the specific situation the students just witnessed and the open-ended format of the question enables a more individualized picture of student understanding than does multiple choice. However, many students answer the openended questions briefly and earn a score that may under-represent their true understanding.

Taken as a whole, student performed experiments were more effective at repairing students' misconceptions in heat transfer than were demonstrations, although the difference between the two methods was not uniform in across concept area - the effect size for the Radiation 
experiment advantage with large, while that for the Rate vs. Amount advantage was small. In future work, we plan to further explore the impact of concept area. While experiments are clearly better, the difference in educational effectiveness is small enough that demonstration may be a compelling alternative, particularly for instructors who don't have access to laboratories.

The result that demonstration is useful educationally may appear to be at odds with some previous work (13-15). We believe the positive outcomes from the demonstrations described here stem from two key elements that are lacking from the most common implementations of class demos. First, students are prepared for the demonstration by answering a prediction question that primes them to look closely at the relevant aspects of the demonstration. This is cited as a key practice for learning from demonstrations by Crouch et al (14). Second, the experiments target conceptual understanding, not the derivation of specific modeling relations or laboratory procedures. Finally, students respond to reflection questions at the conclusion of the demonstration, encouraging retention of what they've observed.

Free access to both IBLA modes described in this paper is available through the Concept Warehouse (16), https://jimi.cbee.oregonstate.edu/concept_warehouse/, along with the HECI, handouts, and instructions.

\section{Acknowledgements}

This work was funded by the National Science Foundation, DUE \#1225031.

\section{Works Cited}

[1] Vigeant, M., Dahm, K., and Silverstein, D. 2017. The state of the chemical engineering curriculum: Report from the 2016 survey. American Association for Engineering Education.

[2] Hofstein, A. and Lunetta, V. N. 1980. The Role of the Laboratory in Science Teaching: Research Implications.

[3] Hofstein, A. and Lunetta, V. N. 2004. The laboratory in science education: Foundations for the twenty-first century. Sci. Ed. 88, 1, 28-54. DOI=10.1002/(ISSN)1098-237X.

[4] Hofstein, A. and Kind, P. M. 2012 Learning in and from science laboratories. In Second International Handbook of Science Education,

[5] Bransford, J., Brown, A., and Cocking, R. 2000 How People Learn: Brain, Mind, Experience and School. Commission on Behavioral and Social Science and Education, National Research Council.

[6] Prince, M., Vigeant, M., and Nottis, K. 2009. A preliminary study on the effectiveness of inquiry-based activities for addressing misconceptions of undergraduate engineering students. Education for Chemical Engineers. 4, 2, 29-41.

[7] Prince, M., Vigeant, M., and Nottis, K. 2010. Assessing misconceptions of undergraduate engineering students in the thermal sciences. International Journal of Engineering Education. 26, 4, 880-890.

[8] Prince, M., Vigeant, M., and Nottis, K. 2011. Using inquiry-based activities to repair student misconceptions related to heat, energy, and temperature. Research in Engineering Education Symposium. 
[9] Prince, M., Vigeant, M., and Nottis, K. 2012. Assessing the prevalence and persistence of engineering students' misconceptions in heat transfer. Journal of Engineering Education. 101, 3, 412-438.

[10] Vigeant, M., Prince, M., and Nottis, K. 2012. Making their brains hurt: Quick and effective activities for thermodynamics. Proceedings of the American Association for Engineering Education.

[11] Vigeant, M., Prince, M., and Nottis, K. 2011. Fundamental Research in Engineering Education. Development of concept questions and inquiry-based activities in thermodynamics and heat transfer: an example for equilibrium vs. steady-state. Chemical Engineering Education. 45, 3, 211-218.

[12] Vigeant, M., Prince, M., Nottis, K., Koretsky, M., and Ekstedt, T. 2016. Hands-on, Screens-on, and Brains-on Activities for Important Concepts in Heat Transfer. American Association for Engineering Education.

[13] Lindsay, E. D. and Good, M. C. 2005. Effects of Laboratory Access Modes Upon Learning Outcomes. IEEE Trans. Educ. 48, 4, 619-631. DOI=10.1109/TE.2005.852591.

[14] Crouch, C. H., Fagen, A. P., Callan, J. P., and Mazur, E. 2004. Classroom Demonstrations: Learning Tools or Entertainment? American Journal of Physics. 72, 835-838.

[15] Sharma, M., Johnston, I., Johnston, H., Varvell, K., Robertson, G., Hopkins, A., Stewart, C., Cooper, I., and Thornton, R. 2010. Use of interactive lecture demonstrations: A ten year study. Phys. Rev. ST Phys. Educ. Res. 6, 2, 10.1103/PhysRevSTPER.6.020119.

[16] Koretsky, M., Falconer, J., L., Brooks, B., Gilbuena, D., Silverstein, D., Smith, C., and Miletic, M. 2014. The AIChE Concept Warehouse: A web-based tool to promote conceptbased instruction. Advances in Engineering Education. 4(1), 1-27. 